\title{
Effects of a flipped classroom approach on learning outcomes of higher and lower performing medical students: A new insight
}

\author{
Sandeep Bansal ${ }^{1^{*}} \quad$ Minakshi Bansal $^{2} \quad$ Kashif A Ahmad $^{3} \quad$ Jyotsna Pandey $^{4}$
}

\begin{abstract}
Traditional lecture style instructional method is being replaced with innovative approaches that support active and self-directed learning in medical education. Despite increasing literature on novel pedagogies, educators are faced with mixed reviews on the impact of these approaches on the improvement of student learning. We explored student attitudes and measured learning outcomes using the flipped classroom approach within a single organ system module. Second year medical students received video-recorded lectures and handouts on selected pharmacology and pathology topics in the endocrine and reproductive module as learning resources. Students were required to study prior to attending the scheduled in-classroom knowledge application sessions focusing on critical thinking. Analysis of examination data $(\mathrm{n}=235)$ of summative assessments showed $13 \%$ improvement in mean exam score of class on the selected topics compared to the previous class taught using traditional lecture approach. Lower $27 \%$ of class scored greater on the most difficult exam items compared to the traditional class. Performance of upper $27 \%$ students of both classes was found to be comparable on all selected exam items. In our study, the flipped classroom was perceived as a preferred instructional approach for student learning, and seemed to improve learning outcomes primarily of lower performing students on difficult concepts. The findings of this study can be useful in informing ongoing curriculum refinements in medical schools while selecting innovative active learning instructional methods and making best use of them.
\end{abstract}

Keywords: learning outcomes, application of knowledge, active learning, assessment, engagement

\section{Introduction}

In the past decade, there has been immense interest in studying the effectiveness of teaching methods for medical students. Recent trends in the basic sciences curriculum in medical education are focused on searching for novel instructional methods to foster application of medical science knowledge. This aim is to stimulate critical thinking and facilitate long-term retention of knowledge $^{[1-4]}$. Medical knowledge is growing at a rapid pace, challenging medical educators in selecting which topics to cover and in determining the appropriate breadth and depth of knowledge. Additionally, faculty must select

Received: Nov. 26, 2019; Accepted: Jan. 14, 2020; Published: Feb. 6, 2020

Correspondence to: Sandeep Bansal, Department of Medical Education, TCU and UNTHSC School of Medicine, Fort Worth, TX 76107, USA; Email: sbansals@ gmail.com

${ }^{1}$ Department of Medical Education, TCU and UNTHSC School of Medicine, Fort Worth, TX 76107, USA

2 Harris College of Nursing and Health Sciences, Texas Christian University, Fort Worth, TX 76109, USA

${ }^{3}$ Carle Illinois College of Medicine, University of Illinois-Urbana Champaign, IL 61820, USA

${ }^{4}$ Central Michigan University, College of Medicine, MI 48859, USA

Citation: Bansal S, Bansal M, Ahmad KA, et al. Effects of a flipped classroom approach on learning outcomes of higher and lower performing medical students: A new insight. Adv Educ Res Eval, 2020, 1(1): 24-31.

Copyright: $\odot 2020$ Sandeep Bansal, et al. This is an open access article distributed under the terms of the Creative Commons Attribution License, which permits unrestricted use, distribution, and reproduction in any medium, provided the original author and source are credited. the most effective content delivery method to utilize contact time most efficiently ${ }^{[5,6]}$. It is well documented that the learning process is significantly enhanced when students are motivated and actively engaged in the learning process ${ }^{[4,7-10]}$. Many medical schools have capitalized on these processes and have implemented innovative pedagogical approaches (problem-based learning, team-based learning, etc.) in an attempt to maximize student learning ${ }^{[11]}$. While many educators report that this modernization of education delivery has benefits, there is no compelling evidence that it enhances factual knowledge acquisition or deeper understanding of underlying concepts $^{[12]}$.

Educators have sought to change the learning environment by shifting the focus from instructor to student participation. Recently, medical education has become fond of the flipped classroom approach ${ }^{[13-17]}$. Although the flipped classroom serves as a paradigm shift in medical education, it is by no means is a novel concept. The approach has been successfully used in other disciplines such as law and physics ${ }^{[6]}$. In flipped classrooms, the instructor effectively shifts learning from the instructor's space to the individual learner's space. In the traditional lecture-based teaching approach, the instructor 
delivers information in class and students gather information through passive listening. A flipped classroom employs a change in the order of learning steps normally observed in traditional didactic instructional approaches. In the flipped classroom approach students read the topic before attending class by using learning objectives and learning resources usually provided to them electronically. Learning resources typically include short videos on the topic and assigned e-readings. The self-paced advanced preparation is then followed by instructorfacilitated scheduled classroom sessions where time is utilised for practicing relevant problems requiring application of knowledge ${ }^{[2,8]}$. This method lends itself particularly well to basic science courses such as pharmacology and pathology, which require deep understanding of mechanisms for application of knowledge to clinical medicine.

In recent years, literature exploring the efficacy of the flipped classroom in medical education has increased ${ }^{[18]}$. The approach has found increasing popularity and acceptance among educators; however, data on its impact on learning outcomes, as assessed by exam performance, of medical students with different academic caliber is lacking. The present study was designed to explore the effectiveness of flipped classroom in delivering selected pharmacology and pathology topics to medical students. The study examined both student attitudes as well as student performance on exams.

\section{Methods}

\subsection{Study design and participants}

We conducted this quasi-experimental study at Ross University School of Medicine (RUSM), Dominica. The participants $(n=235)$ were the second-year (fourth semester) medical students. The RUSM Institutional Review Board granted ethical approval for the study.

\subsection{Approach}

In the school's organ systems-based spirally integrated curriculum, we examined the flipped classroom approach in a subsection of an organ system module, the endocrine and reproductive module, for the selected pharmacology and pathology content (pharmacology of diabetes mellitus and pathophysiology of male reproductive disorders). We selected a total of four out of twelve hours of classroom instruction time to study endocrine pharmacology and reproductive pathology using the flipped classroom approach.

Learning objectives, handouts as well as the previously recorded video lectures were made available to students for pre-reading ten days prior to the scheduled in-classroom knowledge application session. The video recordings for each topic were of less than 45 minutes duration. As classroom lectures were video-recorded and archived, we availed the previous semester's recordings on these topics to splice out non-teaching time clips (for example, time consumed in students asking questions and instructors answers, waiting times as students read an instructor poised question before answering) as well as other irrelevant pieces in order to make them crisp and tightly concept-oriented to the topics. All students were e-mailed specific instructions about using the posted electronic resources for pre-reading before the inclassroom knowledge application session of the flipped classroom. The students could access these resources remotely for self-study, at their convenience.

The remaining endocrine pharmacology and reproductive pathology topics were delivered as traditional lectures in which students were neither provided prerecorded lectures nor were they expected to read handouts on these topics before the scheduled lectures.

The classroom instructional structure was to utilize the available time for problem-solving and application of knowledge acquired via pre-reading. These in-classroom sessions were named as Interactive Knowledge Application Session (IKAS). Microphones were available on student desks at multiples sites in the classroom converted into a collaborative learning space. Students worked in small groups to complete, on average, a series of twelve clinical vignette-based multiple-choice questions requiring higher-order thinking during a ninety minute session. The questions were projected on the LCD screen. On each question, students were given three minutes for small group discussion and select their group answers. Group responses were recorded and projected on LCD using TurningPoint (Turning Technologies, Youngstown, $\mathrm{OH})$, an audience response system. Faculty members $(\mathrm{SB}, \mathrm{JP})$, the content experts, facilitated the sessions and promoted a discussion between groups to allow them to justify their answer choices. Three to four minutes were devoted to this step. The instructor-facilitated discussions ensured that concepts and steps involved in solving the problems were understood by all students.

The reason for selecting endocrine and reproduction module was that both these organ systems are taught in the latter part of year two and by this time students need to be prepared for reflective application of knowledge and multiple level decision-making to generate a differential diagnosis list. In addition, both endocrine and reproductive system pathologies are complex and secondarily affect multiple organs producing a varied, yet overlapping, symptomatology. Pharmacology and 
pathology were specifically chosen as both require application of mechanistic information for clinical decision making based on clinical signs and symptoms. In addition, the two systems were taught by same instructors to ensure similarity of instruction. The selection of pharmacology and pathology lecture topics from the chosen organ system was informed by student feedback.

To promote buy-in from students for the flipped classroom approach the investigators undertook a number of measures including: (a) The rationale and the process were clearly explained to the students during the fourth semester (second year) orientation session; (b) Students were encouraged to voice their concerns and, in addition, they could send their concerns to the two instructors on record (SB, JP) by e-mail or anonymously by leaving their notes in the instructors' departmental mail boxes; (c) An e-mail explaining the process and deemed advantages of this instruction methods was sent to the students after orientation, two weeks prior to the class day, and a day prior as a reminder.

\subsection{Data collection}

To assess effectiveness of the flipped classroom approach, we identified the following outcomes: (a) student perceptions of the flipped classroom; and (b) student exam performance on the selected topics, in the short term.

A 12-item survey was administered to participating second-year medical students of RUSM to assess students' perceptions on the impact of the flipped classroom on their learning and their attitudes towards the flipped classroom approach (Table 1). The survey was organized into two constructs. Construct 1 assessed students' perceptions on the effect of the flipped classroom model on learning. Construct 2 gathered information about students' attitude towards flipped classroom approach. A five-point Likert scale, with response range of strongly disagree, disagree, neutral, agree, and strongly agree, was used for collecting responses.

At the conclusion of the endocrine and the reproductive modules, before exams, students received an electronic link for the survey questionnaire. Answering the survey questionnaire was completely voluntary and anonymous. The first page of the electronic link described purpose of the survey and provided description for informed consent. Electing to proceed to the next page meant giving informed consent to participate in the survey. On the next page, before responding to the survey questionnaire, a question prompted students to report whether they studied the topics in advance of the inclassroom IKAS. The students then proceeded to answer the survey questions.

Student exam scores on the selected items were used to assess the effectiveness of the flipped classroom approach on student learning outcomes. Performance on a total of 9 exam items related to the topics taught by flipped classroom approach was used for outcome comparison. Table 2 shows the themes of these exam items. Performance of previous class, taught by traditional lecture style, on the same exam items was used as external control.

\subsection{Data analysis}

Survey data is reported in percentages. Exams were administered using an exam software, the ExamSoft (ExamSoft Worldwide Inc., Dallas, TX). The software provided exam item analysis, including discriminatin index of the upper and lower $27 \%$ of the class. For the purpose of calculating discrimination index on each exam item, these values are stated to maximize differences in normal distribution while providing enough cases for analysis $^{[19]}$. Upper $27 \%$ and lower $27 \%$ class groups were used to compare difficulty level of the selected exam items between the same category of students of both classes (traditional and flipped). Difficulty level of each exam item for upper $27 \%$ of traditional class was compared with upper $27 \%$ of the flipped classroom, and similarly difficulty level of each item for lower $27 \%$ of the traditional class was compared with lower $27 \%$ of flipped classroom.

\section{Results}

Of the 235 students who were contacted to participate in the post-course evaluation, 98 students (42\%) responded. Out of 98 students, eighty percent (78/98) reported that they studied the topics before participating in the in-classroom IKAS. Seventy-two percent (70/98) of students agreed or strongly agreed that flipped classroom helped with memorization of facts. Fifty-five percent $(54 / 98)$ of students reported that the approach enhanced their understanding of concepts, and 69\% (68/98) agreed or strongly agreed that flipped classroom helped them gauge their own knowledge. Sixty-five percent (64/98) of respondents felt that flipped classroom facilitated them to apply basic science knowledge to clinical application. Although students perceived the flipped classroom as improving their knowledge and application ability, the majority percentage (62/98) remained neutral or disagreed whether it helped them develop systematic approach to learning, and 53\% of respondents (52/98) felt that the flipped classroom did not help them choose a correct response to a practice question. Further, we 
Table 1. Percentage of student responses on the survey questionnaire recording student perceptions and attitudes towards the flipped classroom approach $(\mathrm{n}=98)$

Questionnaire items
Strongly disagree

$(\%)$

\section{Disagree}

$(\%)$

\section{Neutral}

$(\%)$

Agree

$(\%)$
Strongly agree (\%)

1: Questions inquiring what aspect of learning improved by using flipped classroom model

\begin{tabular}{|c|c|c|c|c|c|}
\hline Facilitated memorization of facts & 0.00 & 0.00 & 27.45 & 50.00 & 22.54 \\
\hline Facilitated easier understanding of concepts & 10.78 & 17.64 & 16.66 & 41.17 & 13.72 \\
\hline $\begin{array}{l}\text { Helped analyze clinical application of my } \\
\text { knowledge }\end{array}$ & 8.82 & 12.74 & 13.72 & 41.17 & 23.52 \\
\hline Helped gauge my own knowledge & 12.74 & 9.80 & 9.80 & 39.21 & 28.43 \\
\hline Helped me to engage in learning process & 11.76 & 16.66 & 19.60 & 30.39 & 21.56 \\
\hline $\begin{array}{l}\text { Helped me develop systematic approach to } \\
\text { learning }\end{array}$ & 13.72 & 18.62 & 31.37 & 26.47 & 9.80 \\
\hline $\begin{array}{l}\text { Helped me select correct responses in } \\
\text { practice questions related to the topics }\end{array}$ & 13.72 & 12.74 & 28.43 & 28.43 & 15.68 \\
\hline
\end{tabular}

2: Questions regarding why students preferred the flipped classroom

\begin{tabular}{|c|c|c|c|c|c|}
\hline $\begin{array}{l}\text { Helped me learn better by actively } \\
\text { participating in problem solving }\end{array}$ & 17.64 & 9.80 & 15.68 & 38.23 & 17.64 \\
\hline Helped me in acquiring integrated knowledge & 15.68 & 8.82 & 13.72 & 42.15 & 19.60 \\
\hline Help me to utilize classroom time effectively & 24.50 & 21.56 & 13.72 & 22.54 & 17.64 \\
\hline Helped me to get less help from instructor & 18.62 & 15.68 & 39.21 & 18.62 & 7.84 \\
\hline Will help me perform better on exams & 20.58 & 10.78 & 37.25 & 26.47 & 5.88 \\
\hline
\end{tabular}

observed that, although the majority of the students believed that flipped classroom helped them acquire integrated knowledge, they did not necessarily believe that the flipped classroom model led to the best utilization of classroom time or helped them in seeking less help from the instructor. Remarkably, seventy percentage students (69/98) remained neutral or disagreed that the flipped classroom approach helped them perform better on exams.

Mean score on the exam items related to the nine selected themes (Table 2) improved by $13 \%$ ( $86 \%$ in the flipped classroom versus $73 \%$ in the traditional classroom) in the flipped classroom.

Performance of students $(n=235)$ on individual exam items showed that the flipped classroom helped in improving performance of lower $27 \%$ of class on the difficult questions (Figure 1). There was no noticeable difference in performance of upper $27 \%$ of the class (Figure 2). The format and the type of questions were unchanged and exams were conducted in a similar format between traditional (previous semester) and flipped classroom groups. The most difficult items required higher order of thinking and application of knowledge. One of these most difficult questions, item 8, for example, asked to select an appropriate drug that would increase the levels of endogenous incretins, rather than
Table 2. Themes of examination question items (in increasing level of difficulty from item 1 to 9) related to selected topics delivered by using the flipped classroom approach

\begin{tabular}{l}
\multicolumn{1}{c}{ Themes of Examination Items } \\
\hline 1. Maternal cause of fetal abnormalities \\
2. Penile lesions \\
3. Prostate cancer \\
4. Testicular tumors \\
5. Masking of hypoglycemic symptoms in a type 2 diabetic patient \\
6. Therapeutic role of glucocorticoids in congenital adrenal \\
hyperplasia \\
7. Pharmacokinetic features of antidiabetic drugs for postprandial \\
hyperglycemia \\
8. Mechanism of action of gliptans \\
9. Adverse effects of glucocorticoids
\end{tabular}

asking directly to choose a drug that inhibits dipeptidyl peptidase. A good understanding of the incretin physiology including incretin receptors is required to select the correct answer. Answer choices included exenatide, repaglinide, acarbose, pioglitazone, and sitagliptin (the correct answer). Exenatide, a GPL-1 receptor agonist, an incretin mimetic, which does not increase the levels of endogenous incretins but acts on incretin receptors to mimic incretin actions served as a good distractor. Difficulty level of this question in the traditional as well as the flipped classroom group were near 0.9 in the upper 
$27 \%$ of the class, but in the lower $27 \%$ of the class these numbers were 0.62 and 0.72 , respectively.

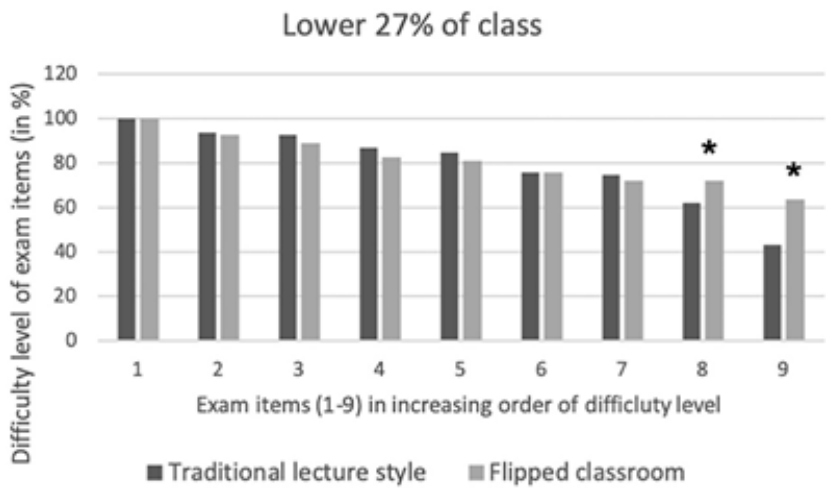

Figure 1. Performance of lower performing students (lower $27 \%$ of class) in the flipped classroom approach versus traditional lecture style $(n=235)$

$\mathrm{X}$-axis shows exam items (Table 2) in increasing order of difficulty from left to right. Y-axis shows difficulty level of exam items. Items 8 and 9 show noticeable improvement in the flipped classroom approach.

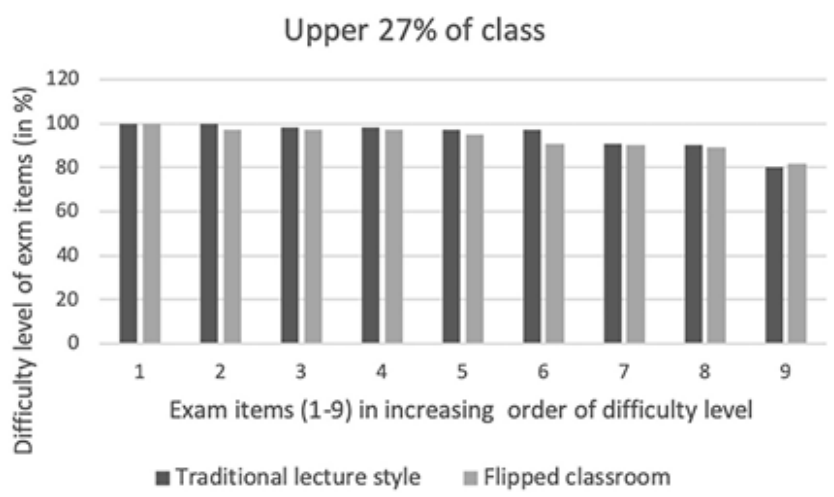

Figure 2. Performance of higher performing students (upper $27 \%$ of class) in the flipped classroom approach versus traditional lecture style $(\mathrm{n}=235)$

$\mathrm{X}$-axis shows exam items in increasing order of difficulty from left to right. Y-axis shows difficulty level of exam items. No significant difference between the two groups noticed.

The second-most difficult question, item 9, provided presenting symptoms as increased appetite, polyuria, white lesions in the oral cavity, and tiredness in a patient who has been on an immunosuppressing therapy for an autoimmune inflammatory disorder. The students needed to select the drug that was therapeutic for the patient's disorder but caused his presenting symptoms. The answer choices included methotrexate, sirolimus, indomethacin, cyclophosphamide, and methylprednisone (the correct answer). The symptoms of the patient were due to decreased immunity and hyperglycemia that would occur in response to increased gluconeogenesis due to chronic glucocorticoid therapy, in this case, prednisone. Difficulty levels of this question in the traditional versus the flipped classroom group were near 0.8 and 0.82 in the upper $27 \%$ of the class, but in the lower $27 \%$ of the class these numbers were 0.42 and 0.64 , respectively.

\section{Discussion}

The findings of our study on the flipped classroom show that the approach improved learning outcomes, as indicated by the exam performance, of lower performing medical students of a class more than higher performing students. This suggests that the flipped classroom may not impact learning outcomes of all students equally. Our findings can contribute to the designs of other researchers' studies as well as in designing teaching-learning sessions to ensure that they fulfill the needs of all types of leaners.

Given the current situation of an exponential increase in medical information coupled with medical educators attempting to make medical information comprehensible and retainable for medical students, medical schools are investing a great deal of time and effort to refine their existing curricula. These attempts have been focused primarily on employing innovative pedagogies to foster active learning while doing away with passive transmission of information in the form of traditional didactic classroom lectures ${ }^{[18]}$. Among a number of innovative instructional methods, such as problem-based learning, team-based leaning, case-based learning, and flipped classroom, there is mixed or at least not unequivocal support yet for a single approach that has been found to be the most effective method in achieving effective utilization of available classroom time in improving students learning outcomes and long term retention of knowledge. ${ }^{[12,18,20]}$ Moreover, it is not clear how the flipped classroom approach impacts learning outcomes of medical students of different academic caliber in a cohort. Considering these questions, the present study employed a flipped-classroom model to study its effectiveness in improving student learning outcomes at RUSM.

A number of studies have shown acceptance of flipped approach by students. ${ }^{[10,13-16,18]}$ The results of our study were congruent with these previous studies as far as perception of the flipped classroom is concerned. Students in the present study believed that the flipped classroom significantly helped them understand the material, identify their learning needs by gauging their knowledge, and increased their engagement in the learning process. We believe that in the present day where information can be 
accessed easily from a variety of resources available on internet or is made available by instructors online, utilizing classroom time for transmission of information would be injudicious. With changed views on approaching learning it is important for students to adapt to new innovative trends in education to become more independent and active learners, and not to rely on passive delivery of content by the professor. The present era of modern medical education is no longer about only gathering knowledge, but is more about being a problem-solver in applying knowledge ${ }^{[21]}$.

Studies have shown that learning key material prior to class enabled students to engage in active-learning exercises with more focus, confidence, and enthusiasm ${ }^{[17]}$. Studying a topic in advance to participating in the inclassroom application sessions is vital in making the flipped-classroom approach successful. In our study, $80 \%$ of students reported that they studied the assigned topics before attending the in-classroom knowledge application sessions. Our experience of using flipped classroom approach taught us that in order to achieve the goal of $100 \%$ student participation in completing the pre-reading task, we could have emphasized it more in conveying the importance of pre-reading for the success of the flipped classroom approach. Although we sent multiple emails to students explaining the learning process involved in flipped classroom and expectations from students, separate reminders to complete prereading could have provided a greater impact. Additionally, introducing student accountability for pre-reading by means of using a grading rubric containing items on peer-evaluation and assigning group scores could have improved pre-reading participation. This approach can provide the student the reward of social recognition by the group. The group recognises the participating student as a worthy group member who benefits the group in promoting robust discussions around application exercises $^{[22]}$.

In the present study the outcome of the flipped classroom on learning was evident from the overall $13 \%$ increase in mean score of the class on items related to the selected topics taught by flipped classroom approach compared to the previous class that was taught by traditional lecture approach. Other studies on the flipped classroom approach have also shown improvement in overall exam performance in different subjects ${ }^{[9,23-25]}$. Further dissection of exam results by using exam item analysis revealed that the outcome on exam items of higher performing students (the upper 27\%) of the class was not much different from the traditional approach. However, the performance of lower performing students (lower 27\%) on the two most difficult exam items was improved by $10 \%$ and $22 \%$, respectively, by the flipped approach compared to the traditional lecture style approach. We deduced that this could be because students who are high performers are more likely to have acquired independent learning methods for deep learning prior to coming to medical school. Our findings also suggest that for high performing students, instructional method may not impact their self-learned and self-managed learning process.

In contrast, lower performing students could find the flipped classroom approach valuable in deeper learning of the material, which translated into better performance on exam items previously considered difficult by traditionally taught group. Learning of difficult concepts by working through the problems is an efficient way that helps in creating connections between pieces of knowledge related to the topic across subjects. Another explanation supporting the ability of lower performers to reap the benefits of flipped classroom could be due to the reported variation in learning styles of undergraduate and postgraduate students. Undergraduates are predominantly activists and theorists and learn better by participating in interactive discussions involved in problembased and case-based learning ${ }^{[26]}$. Postgraduates commonly have the "reflector" learning style where they learn more by self-critique and analysis ${ }^{[26]}$. Compared to high performing medical students who can be considered to represent postgraduate style of learning, lower performing group that can be considered to represent undergraduate style of learning could benefit more from the newly introduced active learning via flipped classroom. In contrast, higher performers who possibly already possess "reflector" learning style, flipped classroom may not impact their learning habits. A study that investigated the effect of flipped classroom on graduate students, a genre representing students who have acquired efficient learning styles, reported little difference on performance of students taught by flipped classroom compared to traditional approach ${ }^{[20]}$. The results of the present study may suggest that the flipped classroom approach helped in moving lower-performers from the undergraduate mode to more developed graduate mode of learning. It appears that the active learning approach derived from the flipped classroom model is more beneficial in improving problem-solving skills in lower performing students compared to higher performers.

Students commented that while they believed this model improves knowledge, retention of knowledge, and integration, it impacts negatively on their time and workload (Table 3). Despite this negative opinion, their exam scores reveal an improvement in performance that aligns with their positive perceptions of the flipped classroom. 
Table 3. Themes of students' open comments on flipped classroom experience

\begin{tabular}{lc}
\hline \multicolumn{1}{c}{ Identified theme } & Number of student comments \\
\hline Reinforces knowledge & 8 \\
Better retention of knowledge & 5 \\
Helps in integration with clinical & 15 \\
knowledge & 6 \\
Enhances application & 24 \\
Time constraints; increases workload & \\
\hline
\end{tabular}

Other studies also suggest that blending new teaching modalities with interactive classroom activities can result in improved learning but do not guarantee improved student satisfaction $^{[25]}$.

\section{Limitations}

Attendance was not mandatory for students, and the student responses on the survey questionnaire were anonymous; thus, it was not possible to link the responses of respective students to their individual exam performances. Additionally, the results of the study are institution- and topic- specific, which limits generalization of the findings.

In the future, the authors are designing a study to measure long-term benefits of flipped classroom on retention and application of knowledge in medical practice by extending this study to later years of medical school and to residency, as well as to study the impact of flipped approach on performance on all three step exams of the United States Medical Licensing Examination.

\section{Conclusion}

Our results indicate that majority of medical students find the flipped classroom approach beneficial to their learning. In addition, the approach appears to be effective in improving exam performance. However, the approach may not result in equal gains to medical students of varying academic caliber. In our study, the flipped classroom approach appears to benefit primarily the lower performing students of a class in understanding difficult concepts and performing better on the difficult exam items, compared to the traditional didactic style of teaching. More studies from different educational institutions will be useful in generalizing the results of our study. Meanwhile, the findings of our study can be useful for the medical educator to be aware that "one size does not fit all" as they attempt to strike a balance in incorporating active learning instruction to achieve better learning outcomes for all students regardless of their different learning styles. We trust our study will provide impetus to curriculum reforms in an era where medical education is transforming rapidly to incorporate active and self-directed learning.

\section{Conflict of interest and funding}

The authors declare that there is no conflict of interest and no financial support.

\section{References}

[1] Heath C and Heath D. Made to stick: why some ideas survive and others die. 1st ed. New York: Random House, 2007.

[2] Prober CG and Heath C. Lectures halls without lecturesA proposal for medical education. New England Journal of Medicine, 2012, 366(18): 1657-59. https://doi.org/10.1056/NEJMp1202451

[3] Rhee EP, Scott JA and Dighe AS. Case records of the Massachusetts General Hospital. Case 4-2012. A 37-year-old man with muscle pain, weakness, and weight loss. New England Journal of Medicine, 2012, 366(6): 553-560. https://doi.org/10.1056/NEJMcpc1110051

[4] Shatto B, L'Ecuyer K and Quinn J. Retention of content utilizing a flipped classroom approach. Nursing Education Perspectives, 2017, 38(4): 206-208. https://doi.org/10.1097/01.NEP.0000000000000138

[5] Densen P. Challenges and opportunities facing medical education. Transactions of the American Clinical and Climatological Association, 2011, 122(122): 48-58.

[6] Berrett D. How "Flipping" the classroom can improve the traditional lecture. In: The Chronicle of higher education, 2012.

https://www.chronicle.com/article/

How-Flipping-the-Classroom/130857

[7] Muller JH. Increasing the value of small-group learning. Acadamic Medicine, 2000, 75(5): 518. https://doi.org/10.1097/00001888-200005000-00038

[8] Goldberg HR, Haase E, Shoukas A, et al. Redefining classroom instruction. Advances in Physiology Education, 2006, 30(3): 124-127.

https://doi.org/10.1152/advan.00017.2006

[9] Tune JD, Sturek M and Basile DP. Flipped classroom model improves graduate student performance in cardiovascular, respiratory, and renal physiology. Advances in Physiology Education, 2013, 37(4): 316-20. https://doi.org/10.1152/adva

[10] Fatima SS, Arain FM and Enam SA. Flipped classroom instructional approach in undergraduate medical education. Pakistan Journal of Medical Sciences, 2017, 33(6): 14241428. https://doi.org/10.12669/pjms.336.13699

[11] Lee RM and Kwan CY. The use of problem-based learning in medical education. Journal of Medical Education, 1997, 1(2): 149-158. https://pdfs.semanticscholar.org/fdd9/ 20b04c0ee39c89851ca0f5f032d17e 
[12] Hartling L, Spooner C, Tjosvold L, et al. Problem-based learning in pre-clinical medical education: 22 years of outcome research. Medical Teacher, 2010, 32(1): 28-35. https://doi.org/10.3109/01421590903200789

[13] Veeramani R, Madhugiri VS and Chand P. Perception of MBBS students to "Flipped class room" approach in neuroanatomy module. Anatomy and Cell Biology, 2015, 48(2): 138-143. https://doi.org/10.5115/acb.2015.48.2.138

[14] Evans KH, Thompson AC, O'Brien C, et al. An innovative blended preclinical curriculum in clinical epidemiology and biostatistics: Impact on student satisfaction and performance. Academic Medicine, 2016, 91(5): 696-700. https://doi.org/10.1097/ACM.0000000000001085

[15] Street SE, Gilliland KO and McNeil C. The flipped classroom improved medical student performance and satisfaction in a pre-clinical physiology course. Medical Science Educator, 2014, 25(1): 35-43. https://doi.org/10.1007/s40670-014-0092-4

[16] Ramnanan C and Pound L. Advances in medical education and practice: student perceptions of the flipped classroom. Advances in Medical Education Practice, 2017, 8: 63-73. https://doi.org/10.2147/AMEP.S109037

[17] McLaughlin JE, Griffin LTM, Esserman DA, et al. Pharmacy Student Engagement, Performance, and Perception in a Flipped Satellite Classroom. American journal of Pharmaceutical Education, 2013, 77(9): 196. https://doi.org/10.5688/ajpe7

[18] Chen F, Lui AM and Martinelli SM. A systematic review of the effectiveness of flipped classrooms in medical education. Medical Education, 2017, 51: 585-597. https://doi.org/10.1111/medu.13272

[19] Wiersma W and Jurs S. Educational measurement and testing. Needham Heights, MA: Allyn and Bacon, 1990.
[20] Riddell J, Jhun P, Fung CC, et al. Does the Flipped classroom Improve Learning in Graduate Medical Education. Journal of Graduate Medical Education, 2017, 9(4): 491496. https://doi.org/10.4300/JGME-D-16-00817.1

[21] Kalantzis M and Cope B. New Learning: Elements of a Science of Education. 2nd ed. New York: Cambridge University Press, 2012.

[22] Stein RE, Colyer CJ and Manning J. Student Accountability in Team-Based Learning Classes. Teaching Sociology, 2016, 44(1): 28-38. https://doi.org/10.1177/0092055x15603429

[23] Koo CL, Demps EL, Farris C, et al. Impact of Flipped Classroom Design on Student Performance and Perceptions in a Pharmacotherapy Course. American Journal of Pharmaceutical Education, 2016, 80(2): 33. https://doi.org/10.5688/ajpe80233

[24] Munson A and Pierce R. Flipping Content to Improve Student Examination Performance in a Pharmacogenomics Course. American Journal of Pharmceutical Educucation, 2015, 79(7): 103. https://doi.org/10.5688/ajpe797103

[25] Missildine K, Fountain R, Summers L, et al. Flipping the classroom to improve student performance and satisfaction. Journal of Nursing Education, 2013, 52(10): 597-599. https://doi.org/10.3928/01484834-20130919-03

[26] Shukr I, Zainab R and Rana MH. Learning styles of postgraduate and undergraduate medical students. Journal of College and Physician Surgeon Pakistan, 2013, 23(1): 2530 https://doi.org/01.2013/JCPSP.2530 